Original article

\title{
Distress tolerance in methamphetamine and opium abusers with non-drug abuser (A comparative analysis)
}

\author{
Jalal Shakeri, Vahid Farnia, Omran Davarinejad, Safora Salemi*, Sanobar Golshani, \\ Bahareh Rahami, Mostafa Alikhani, Sara Hookari \\ Department of Psychiatry, Substance Abuse Prevention Research Center, Health Institute, Kermanshah University of Medical Sciences, Kermanshah, Iran
}

\section{A R T I C L E I N F O}

\section{Keywords:}

Distress tolerance

Methamphetamine

Opium

\begin{abstract}
A B S T R A C T
Introduction: Evidence suggests that the way of enduring emotional distress plays a role in the tendency of people to abuse drugs. Accordingly, the present study aims to compare the distress tolerance in metamphetamines and drug abusers with non-drug abusers.

Methodology: The current study is an analytical study. The statistical population includes all the patients abusing methamphetamine and opium as well as non-drug abuser individuals visiting Farabi Hospital of Kermanshah in western Iran in 2018. Among the population, 202 individuals (50 individuals abusing methamphetamine, 52 individuals abusing opium, and 100 non-addicted individuals) were selected using convenient sampling, and then they were approximately matched based on demographic variables. The data were collected using the Distress Tolerance Scale developed by Simons and Gaher and were analyzed using multi-variate analysis of variance (MANOVA) and one-way analysis of variance in SPSS20 statistical software application.

Results: The finding analysis showed that the score of the concept of absorption by negative emotions (The subscale of distress tolerance) was significantly different between non-drug abusers and methamphetamine abusers $(\mathrm{P}<0.05)$. The mean scores of distress mental evaluation and the overall score of emotional distress tolerance were also statistically significant between non-drug abusers and methamphetamine abusers as well as non-drug abusers and opium abusers. However, this difference was not significant between methamphetamine abusers and opioid abusers $(\mathrm{P}>0.05)$.

Conclusion: The findings of the current study show that patients abusing opium and methamphetamine are less capable of tolerating distress compared to non-drug abuser.
\end{abstract}

\section{Introduction}

Today, drug use and its unpleasant consequences are among the most important public health problems worldwide. Drug use not only causes pain and suffering in user, but also affects the community and families. ${ }^{1}$ In Iran, the changing pattern of drug use from traditional types to industrial and chemical drugs and the use of stimulants has been considered for several years as a serious threat. Opium's are chemical drugs with stupefying effects. ${ }^{2}$ On the other hand, industrial drugs are a combination of traditional drugs with chemical drugs. ${ }^{2}$ Among the industrial drugs, methamphetamine can be mentioned. Methamphetamine increases the body metabolism and creates a state of vitality, increases consciousness and gives the user a sense of increased energy. ${ }^{3}$ It is highly addictive and causes more damage to the person than other amphetamines. ${ }^{3,4}$

The evidence shows that experiencing negative emotions and avoiding negative emotional states as well as distress tolerance are related to incompatibility, ${ }^{5}$ antisocial behaviors, ${ }^{6}$ anxiety issues, ${ }^{7}$ and tendency to abuse alcohol and drugs. ${ }^{8-10}$ Distress tolerance is defined as the individual's capability to experience and tolerate negative emotional states. ${ }^{11}$ In fact, distress tolerance is a variable referring to the capacity for experiencing and resisting emotional distress and discomfort. ${ }^{12}$ People with low distress tolerance usually resort to some destructive behaviors such as drug abuse in order to cope with their own negative emotions, and drug abuse can temporarily result in rapid decrease of their negative emotions. ${ }^{1,13}$

Based on Seo and Kwon model, when an individual is distressed due to specific negative events, he or she will be seeking mitigation and reduction of distress through performing specific tasks. For addicts, a significant distress improving behavior is to take drugs, and doing this will help the individual to avoid the distressing situation. Therefore, in theory, people who can better tolerate distress will be more capable

\footnotetext{
* Corresponding author.

E-mail address: psy.salemi@gmail.com (S. Salemi).
} 
when experiencing negative emotions and troubling situations, so they are less inclined to resort to risky behaviors such as consuming alcohol or taking drugs. ${ }^{14}$

In this regard, Buckner et al. carried out a study to investigate distress tolerance in people abusing cannabis and alcohol. They showed that lack of distress tolerance could play a major role in increasing the problems of people abusing cannabis. ${ }^{8}$ In another study, Howell et al. showed that low distress tolerance had a significant impact on tendency to abuse alcohol. ${ }^{10}$ Kaiser et al. evaluated 522 college students and realized that negative emotions and distress tolerance could be good predictors for drug abuse. ${ }^{1}$ Since opioids are drugs that reduce the ability to respond to stimuli by slowing down the activities of the central nervous system and physical senses, ${ }^{15,16}$ and methamphetamines increase alertness and general arousal and have a different function than that of the opioids, ${ }^{3,17}$ and these two groups of drugs have different psychological impacts, in this study, these two groups of drugs were compared together and to the general population. Moreover, while distress tolerance is a basic factor in the etiology of drug dependence, and some studies have considered this variable, few studies have compared distress tolerance and its subscales in dependence to various drugs and have compared this variable between addicts and non-abuser.

The research gap the current study was trying to fill was the fact that during the initial review, the authors found out that there was no study on evaluating the extent of distress tolerance and comparing distress tolerance in people abusing methamphetamine and opium. Therefore, the current study aims to compare distress tolerance in methamphetamine and opium abusers with non-drug abuser in West of Iran.

\section{Methods}

\subsection{Research design and setting}

The present study was approved by ethics committee of Kermanshah university of medical sciences, Kermanshah, Iran (KUMS.REC.227). This is an analytical study that was conducted to evaluate and compare the score of distress tolerance in people with methamphetamine and opium abusers and non-drug abuser.

The study population included all patients with methamphetamine or opium abuser who referred to Farabi hospital in Kermanshah, Iran, in 2018. Healthy non-relative attendants were considered as control group. People in the control group were selected among the family members of addicts who were visiting their patients in the hospital. The members of the control group were selected among these individuals because of their similar social and economic state to the addicts group, allowing a better matching between the control and case group.Diagnosis of methamphetamine or opium dependence was confirmed by a psychiatrist based on the DSM-IV-TR structural interview. The inclusion criteria were age range of 20-50 years, having at least guidance school literacy, Diagnosis of methamphetamine or opium dependence based on DSM-IV-TR criteria and exclusion criteria included: Having diagnostic criteria for other psychiatric disorders, any medical comorbidities, history of alcohol abuse over the past 5 years, more than one substance addiction at the same time.

In order to evaluate the participants with regards to the inclusion and exclusion criteria, these criteria were explored by the psychologists and psychotherapists working in the hospital. Along with interviewing the participants, their medical records were also evaluated.

The statistical population was selected through available sampling method and assigned to three groups of patients with methamphetamine abuser, opium abuser and non-drug abuser group. 50 patients as methamphetamine group, 52 as opium group and 100 as normal group entered in the study.

The size of the sample was determined according to the study by Howell et al. ${ }^{10}$ In order to increase the test power, the control group was twice as much as the other group.

The non-drug abuser was controlled with regards to age, gender, education level, occupational level, and marital status. To ensure that the non-drug abuser, who were among the patients' companions, had no drug dependence, they were assessed by a psychiatrist based on a structured DSM-5 interview after obtaining informed consent from them.

The sampling methodology was as follows: after the initial proposal of the study design was approved by the Medical University of Kermanshah and the Ethical Committee, the researchers visited Farabi Psychological Hospital in Kermanshah, where participants were to be selected from, from March 21, 2018 to October 23, 2018. After visiting the hospital, the authored coordinated with the president of the hospital and in a session with the psychologists and psychotherapists treating addicts in the hospital, the authors explained the objectives of the current study. Afterwards, based on the inclusion and exclusion criteria, the initial samples were identified. At the next step, the research team and the hospital personnel performed deep evaluations and selected qualified participants who were willing to participate and provided informed consent to participate in the study. Then, the researcher provided the necessary explanations to the participants on how to accurately fill out the questionnaires. The participants were informed that at any stage of the process of filling out the questionnaires, they can ask the researcher for more information in case they encounter any difficulty. It is worth mentioning that the questionnaires were filled out individually and in the presence of the researchers.

\subsection{Measures}

\subsubsection{Distress tolerance scale}

The distress tolerance scale made by Simons and Gaher is a 15points self-referential tool. The items in this questionnaire are scored based on a five-option Likert spectrum (1: completely agree; 2: agree; 3: no opinion; 4: disagree; 5: completely disagree) and the options have a score of $1,2,3,4$, and 5 , respectively. Higher scores in this questionnaire indicate higher distress tolerance. In order to obtain the total score for distress tolerance, all the scores for the items in the questionnaire are summed up, and in order to obtain the total score for each of the subscales, the scores for the items in each subscale are summed up together. ${ }^{18}$

The four forms of disturbance tolerance are evaluated by this scale: 1. Tolerance of emotional distress (for example: sadness and distress are unbearable to me); 2. Distress mental evaluation (for example, sadness and distress is always a great exam for me.), 3. Absorption by negative emotions for example: my emotional disturbances are so severe that they are totally dominated me, 4. Set up efforts for distress (for example, when I feel distressed or sadness, immediately I have to look for a solution).

Distress tolerance $(r=-0.51)$ has a negative correlation with dysregulation and has a positive correlation with excitement $(r=0.26)$. Cronbach's alpha coefficients of tolerance, evaluation, absorption and adjustment subscales are respectively 0.74 , 0.77.0.84.0.73. In Iran, Azizi, obtained this test Cronbach's alpha coefficient as $0.86 .^{19}$

\section{Data analysis}

The data collected by the statistic expert were entered into the SPSS20 software and analyzed by relevant analytical methods. The descriptive statistics methods as frequency and percentage were used to determine the distribution of age, gender, marital status, education, occupation as well as the level of emotional distress tolerance, absorption by negative emotions, distress mental evaluation, set up effort for distress, and overall score of emotional distress tolerance. The Chisquare test was used and, if necessary, a Fisher exact test was used to 
examine the homogeneity of demographic variables including age, gender, marital status, occupation and education level. Finally, multivariate analysis of variance (MANOVA) and then univariate variance analysis were used to compare the mean of emotional distress tolerance, absorption by negative emotions, distress mental evaluation, set up effort for distress, and the overall score of emotional distress tolerance among the three groups, after confirming the assumption of the normalization of the score of the concepts examined by drawing the diagram Q-Q, as well as other necessary assumptions. All analyzes were performed using SPSS20 software and at a 5\% error rate.

\section{Ethical considerations}

The study was approved by the ethics committee of the vice chancellery of research and technology, Kermanshah University of Medical Sciences (KUMS.REC.227). In order to follow the ethical principles, the questionnaires were filled out after obtaining the informed consent of the participants, and they were assured that their information would stay confidential.

\section{Result}

50 subjects in the methamphetamine group, 52 subjects in the drug abusers group and 100 subjects in the non-drug abusers were enrolled into the study. The distribution of demographic characteristics of subjects in groups is shown in Table 1 . The association results showed that the three studied groups were suitably similar for demographic characteristics of age, gender, marital status, occupation and education level $(\mathrm{P}>0.05)$ (Table 1).

As shown in Table 2, The mean values of distress tolerance for the selected groups show that the mean values for distress tolerance, mental distress evaluation, and setup effort for distress were the highest for the first group with values of 7.82, 18.92, and 6.83, respectively; while, they were the lowest for the second group with values of 6.83, 16.0, and 5.75 , respectively. The mean score of absorption by negative emotions and in general the total score for emotional distress tolerance was highest for the first group (8.57) and lowest for the third group (7.06).

Then, the multivariate analysis of variance (MANOVA) and Wilks' lambda show that based on the value of the F statistic and its significance level, the effects of the selected groups on the model are significant (Table 3).

The results of the tests for the effects among the participants show that in general, our analysis model as well as the effects of the selected groups on attracting, evaluating, and adjusting the participants were
Table 2

The descriptive Statistics for concepts of distress tolerance among the studied groups.

\begin{tabular}{|c|c|c|c|c|}
\hline variable & group & $\mathrm{N}$ & Min-Max & $\begin{array}{l}\text { Standard } \\
\text { deviation } \pm \\
\text { Mean }\end{array}$ \\
\hline \multirow{3}{*}{$\begin{array}{l}\text { Emotional distress } \\
\text { tolerance }\end{array}$} & Non-Drug Abuser * & 100 & $3-15$ & $7.82 \pm 3.16$ \\
\hline & Opium Abusers* & 52 & $3-15$ & $6.83 \pm 2.83$ \\
\hline & $\begin{array}{l}\text { Methamphetamine } \\
\text { Abusers * }\end{array}$ & 50 & $3-15$ & $7.08 \pm 3.48$ \\
\hline \multirow{3}{*}{$\begin{array}{c}\text { Absorption by } \\
\text { negative } \\
\text { emotions }\end{array}$} & Non-Drug Abuser & 100 & $3-15$ & $8.57 \pm 3.74$ \\
\hline & Opium Abusers & 52 & $3-15$ & $7.23 \pm 3.13$ \\
\hline & $\begin{array}{l}\text { Methamphetamine } \\
\text { Abusers }\end{array}$ & 50 & $3-15$ & $7.06 \pm 3.50$ \\
\hline \multirow{3}{*}{$\begin{array}{c}\text { Distress mental } \\
\text { evaluation }\end{array}$} & Non-Drug Abuser & 100 & $7-30$ & $18.92 \pm 5.35$ \\
\hline & Opium Abusers & 52 & $7-30$ & $16.0 \pm 5.58$ \\
\hline & $\begin{array}{l}\text { Methamphetamine } \\
\text { Abusers }\end{array}$ & 50 & $6-30$ & $16.20 \pm 5.63$ \\
\hline \multirow{3}{*}{$\begin{array}{l}\text { Set up effort for } \\
\text { distress }\end{array}$} & Non-Drug Abuser & 100 & $3-15$ & $6.83 \pm 2.99$ \\
\hline & Opium Abusers & 52 & $3-15$ & $5.75 \pm 2.79$ \\
\hline & $\begin{array}{l}\text { Methamphetamine } \\
\text { Abusers }\end{array}$ & 50 & $3-15$ & 6.20 \\
\hline \multirow{3}{*}{$\begin{array}{l}\text { Overall score of } \\
\text { emotional } \\
\text { distress } \\
\text { tolerance }\end{array}$} & Non-Drug Abuser & 100 & $18-70$ & $42.14 \pm 12.24$ \\
\hline & Opium Abusers & 52 & $18-59$ & $35.81 \pm 11.03$ \\
\hline & $\begin{array}{l}\text { Methamphetamine } \\
\text { Abusers }\end{array}$ & 50 & $19-67$ & $36.54 \pm 12.22$ \\
\hline
\end{tabular}

Table 3

The results for evaluating the effects of the group factor using the multivariate Wilks' lambda test.

\begin{tabular}{lllll}
\hline Effect & Value & ANOVA' F & Sig & Partial Eta Squared \\
\hline intercept & Wilks' Lambda & 540.262 & $0.0001>$ & 0.917 \\
Groups & & 2.175 & 0.029 & 0.042 \\
\hline
\end{tabular}

significant. However, with regards to the effects of the selected groups, there is no significant difference between the selected groups with regards to the mean score for distress tolerance. The adjusted coefficient of determination shows that these groups were able to explain $1 \%, 3 \%$, $54 \%$ and $14 \%$ of the variance in the variables of tolerance, absorption, evaluation, and Set up effort for distress (Table 4).

The following table presents the results of the multivariate Wilks' lambda test for evaluating the significance of the impact of the independent variable (selected groups) on the model, which indicated the significant impact of the selected groups at the error level lower than 5\%.(see Table 5)

Table 1

Distribution of demographic characteristics and association between age, gender, education, occupation, marital status with studied groups.

\begin{tabular}{|c|c|c|c|c|c|c|}
\hline \multirow[t]{2}{*}{ Variable } & & \multicolumn{3}{|l|}{ Groups n(\%) } & \multirow[t]{2}{*}{ Total } & \multirow[t]{2}{*}{$\boldsymbol{x}^{2}$ (Sig) } \\
\hline & & Non-Drug abuser & Opium abusers group & Methamphetamine abuser group & & \\
\hline \multirow[t]{4}{*}{ Age } & $15-25$ & $10(10.0)$ & $7(13.5)$ & $9(18.0)$ & $26(12.9)$ & $11.40(0.07)$ \\
\hline & $26-35$ & 5252.0 & $19(36.5)$ & $27(54.0)$ & $98(48.5)$ & \\
\hline & $36-45$ & $23(23.0)$ & $13(25.0)$ & $12(24.0)$ & $48(23.8)$ & \\
\hline & $>45$ & $15(15.0)$ & $13(25.0)$ & $2(4.0)$ & $30(14.9)$ & \\
\hline \multirow[t]{2}{*}{ Gender } & Female & $7(7.0)$ & $3(5.8)$ & $5(10.0)$ & $15(7.4)$ & $0.72(0.69)$ \\
\hline & Male & 93(93.0) & 49(94.2) & $45(90.0)$ & $187(92.6)$ & \\
\hline \multirow[t]{3}{*}{ Education } & Illiterate and guidance school & $78(78.0)$ & $42(82.4)$ & $42(84.0)$ & $162(80.6)$ & $3.96(0.41)$ \\
\hline & High school to diploma & $15(15.0)$ & $7(23.3)$ & $8(26.7)$ & $30(14.9)$ & \\
\hline & Academic & $7(7.0)$ & $2(3.9)$ & $0(0.0)$ & $9(4.5)$ & \\
\hline \multirow[t]{3}{*}{ Occupation } & Employee & $13(13.0)$ & $8(15.4)$ & 714.0() & 28(13.9) & $1.36(0.85)$ \\
\hline & Self-employed & $28(28.0)$ & $16(30.8)$ & $18(36.0)$ & $62(30.7)$ & \\
\hline & Jobless & $59(59.0)$ & $28(53.8)$ & $25(50.0)$ & $112(55.4)$ & \\
\hline \multirow[t]{3}{*}{ Marital status } & Single & $53(53.0)$ & $21(40.4)$ & $26(52.0)$ & $100(49.5)$ & $7.65(0.10)$ \\
\hline & Married & $40(40.0)$ & $26(50.0)$ & $15(30.0)$ & $81(40.1)$ & \\
\hline & Divorced & $7(7.0)$ & $5(9.6)$ & $9(18.0)$ & $21(10.4)$ & \\
\hline Total & & $100(100.0)$ & $52(100.0)$ & $50(100.0)$ & $202(100.0)$ & \\
\hline
\end{tabular}


Table 4

The results of the study of the significance of the analytical model and the effect of the studied groups.

\begin{tabular}{|c|c|c|c|c|c|c|c|c|}
\hline Source & Dependent Variable & Type III Sum of Squares & $\mathrm{df}$ & Mean Square & $\mathrm{F}$ & Sig & Partial Eta Squared & R Squared(Adjusted R Squared) \\
\hline \multirow[t]{4}{*}{ Corrected Model } & Tolerance & 39.766 & 2 & 19.883 & 1.988 & .140 & .020 & $0.020(0.01)$ \\
\hline & Absorption & 102.984 & 2 & 51.492 & 4.128 & .018 & .040 & $0.040(0.03)$ \\
\hline & Evaluation & 403.135 & 2 & 201.568 & 6.711 & .002 & .063 & $0.063(0.054)$ \\
\hline & Set up effort for distress & 42.457 & 2 & 21.228 & 2.465 & .088 & .024 & $0.024(0.014)$ \\
\hline \multirow[t]{4}{*}{ Intercept } & Tolerance & 9588.702 & 1 & 9588.702 & 958.927 & .000 & .828 & \\
\hline & Absorption & 10615.613 & 1 & 10615.613 & 850.939 & .000 & .810 & \\
\hline & Evaluation & 53081.730 & 1 & 53081.730 & 1767.212 & .000 & .899 & \\
\hline & Set up effort for distress & 7163.983 & 1 & 7163.983 & 831.826 & .000 & .807 & \\
\hline \multirow[t]{4}{*}{ group } & Tolerance & 39.766 & 2 & 19.883 & 1.988 & .140 & .020 & \\
\hline & Absorption & 102.984 & 2 & 51.492 & 4.128 & .018 & .040 & \\
\hline & Evaluation & 403.135 & 2 & 201.568 & 6.711 & .002 & .063 & \\
\hline & Set up effort for distress & 42.457 & 2 & 21.228 & 2.465 & .088 & .024 & \\
\hline \multirow[t]{4}{*}{ Error } & Tolerance & 1989.882 & 199 & 9.999 & & & & \\
\hline & Absorption & 2482.561 & 199 & 12.475 & & & & \\
\hline & Evaluation & 5977.360 & 199 & 30.037 & & & & \\
\hline & Set up effort for distress & 1713.860 & 199 & 8.612 & & & & \\
\hline \multirow[t]{4}{*}{ Total } & Tolerance & 13035.000 & 202 & & & & & \\
\hline & Absorption & 15038.000 & 202 & & & & & \\
\hline & Evaluation & 68208.000 & 202 & & & & & \\
\hline & Set up effort for distress & 10020.000 & 202 & & & & & \\
\hline \multirow[t]{4}{*}{ Corrected Total } & Tolerance & 2029.649 & 201 & & & & & \\
\hline & Absorption & 2585.545 & 201 & & & & & \\
\hline & Evaluation & 6380.495 & 201 & & & & & \\
\hline & Set up effort for distress & 1756.317 & 201 & & & & & \\
\hline
\end{tabular}

Table 5

The results for evaluating the significance of the selected groups for the model using the multivariate Wilks' lambda test.

\begin{tabular}{lllll}
\hline & Value & F & Sig & Partial Eta Squared \\
\hline Wilks' lambda & 0.917 & 2.175 & .029 & .042 \\
\hline
\end{tabular}

Table 6

The results of Univariate tests for concepts of distress tolerance among the studied groups.

\begin{tabular}{|c|c|c|c|c|}
\hline & Variable & Group & $\begin{array}{l}\text { ANOVA' F } \\
\text { (Sig) }\end{array}$ & $\begin{array}{l}\text { Partial Eta } \\
\text { Squared }\end{array}$ \\
\hline \multirow[t]{5}{*}{$\begin{array}{l}\text { Emotional distress } \\
\text { tolerance }\end{array}$} & $\begin{array}{l}\text { Emotional distress } \\
\text { tolerance }\end{array}$ & $\begin{array}{l}(1)^{*} \\
(2)^{*} \\
(3)^{*}\end{array}$ & $\begin{array}{l}1.99 \\
(P>0.05)\end{array}$ & 0.020 \\
\hline & $\begin{array}{l}\text { Absorption by } \\
\text { negative emotions }\end{array}$ & $\begin{array}{l}(1) \\
(2) \\
(3)\end{array}$ & $\begin{array}{l}4.13 \\
(P<0.05)\end{array}$ & 0.040 \\
\hline & $\begin{array}{l}\text { Distress mental } \\
\text { evaluation }\end{array}$ & $\begin{array}{l}(1) \\
(2) \\
(3)\end{array}$ & $\begin{array}{l}6.71 \\
(P<0.05)\end{array}$ & 0.063 \\
\hline & $\begin{array}{l}\text { Set up effort for } \\
\text { distress }\end{array}$ & $\begin{array}{l}(1) \\
(2) \\
(3)\end{array}$ & $\begin{array}{l}2.50 \\
(P>0.05)\end{array}$ & 0.024 \\
\hline & $\begin{array}{l}\text { Overall score of } \\
\text { emotional distress } \\
\text { tolerance }\end{array}$ & $\begin{array}{l}(1) \\
(2) \\
(3)\end{array}$ & $\begin{array}{l}6.40 \\
(P<0.05)\end{array}$ & - \\
\hline
\end{tabular}

Bold values indicate the error level smaller than $5 \%$.

The results of Table 6 show that there is a statistical significance difference between the mean scores of absorption by negative emotions, distress mental evaluation and overall score of emotional distress tolerance among the methamphetamine abuser, opiate and non-drug abuser (all P s < 0.05).

For all of the five concepts, the average score for non-drug abuser is higher than those for opioid and methamphetamine abuser. But compared to the opioid group and the methamphetamine group, it can be seen that, except for the concept of absorption by negative emotions, for other concepts, the mean scores in the methamphetamine group are higher than the opioid group (Table 6).

\section{Discussion}

This study aims to compare distress tolerance in methamphetamine and drug abuser with non-drug abuser. Analysis of the findings showed that there is a significant difference between the overall score of distress tolerance among non-drug abuser and methamphetamine and drug abuser, which mean that the mean tolerance of distress in non-drug abuser is higher than drug abuser, in fact, non-drug abuser can better tolerate distress. These results are consistent with the results of Daughters et al., ${ }^{6}$ Buckner et al., ${ }^{8}$ Howell et al., ${ }^{10}$ Simons et al. ${ }^{13}$ on the positive correlation of distress intolerance with drug-related problems. In the explanation of this finding, it can be argued that people who have high ability to experience distress and can easily absorb and digest their emotions of distress and helplessness tend to be less likely to experience impulse behaviors when experiencing negative emotions, that is, they have less negative emotions and less tend to use drug. ${ }^{5}$ The low ability to tolerate distress leads people, to overcome the annoying emotional state, goes toward unhealthy ways, such as drug abuse, which can also lead to a greater degree of dependency in a defective cycle. It can also be argued that distress intolerance is suggested as a key to explain the basic mechanism of preservation of drug use. Indeed, the possibility of low ability to tolerate distress alone is a significant variable for predicting drug abuse. ${ }^{8,20}$

Among the subscales examined, absorption by negative emotion the highest impact factor was related to the dependent variable., which means that non-drug abuser are less attracted by negative emotions. ${ }^{21}$ This finding is consistent with the studies by Verdejo-García et al., ${ }^{21}$ McKay, ${ }^{22}$ Chen et al. ${ }^{23}$ In explaining this finding, it can be argued that absorption by negative emotions in methamphetamine abuser is due to low emotional skills and inability to solve problems, and it seems that methamphetamine abuser have a poor ability to control emotions and deal with issues and make appropriate decisions. ${ }^{24,25}$ In fact, it can be 
argued that these individuals have insufficient growth in emotions and proper management of emotions and behavior, and when they are under the pressure of friends, peers and others at the onset of drug abuse, they are not able to restrain reuse and control and weak control of their emotions increases the risk of drug use and the onset of the addictive behavior cycle. Accordingly, people with negative emotions are likely to be more prone to use high-risk behaviors as a means to relieve negative emotions. ${ }^{19,26-28}$

Those who show high levels of deficits in set up negative emotions are more likely to show hazardous behaviors like methamphetamine abuse. Also, a significant number of empirical and theoretical evidence suggests that negative emotions and drug-related disorders are related to each other. Usually this relation is conceptualized in the form of a two-part model, where individuals who experience more levels of negative emotions are at increased risk of using drugs and alcohol as a coping mechanism. ${ }^{11,29-31}$ The other finding of the present study was that there was a significant difference between the mean scores of distress mental evaluation in the non-drug abuser group with the methamphetamine and drug users group, which means that in the nondrug abuser group, a better distress mental evaluation was performed. This finding is consistent with Shorey et al. ${ }^{32}$ and Khan et al. ${ }^{33}$

In explaining this finding, it can be said that lower distress mental evaluation and higher negative emotions can be a barrier to controlling drug abuse temptation. Indeed, distress mental evaluation can lessen the perceived negative and harmful consequences of drug use, and therefore, people who consume methamphetamine and drugs fail against psychological and social pressures for drug abuse, and to mental improvement of distress or avoid unpleasant feelings and to avoid negative emotional states, they may be turn to use drugs like methamphetamine and drugs. Research has shown that distress and subsequent negative emotions contribute to the arbitrary use of drugs, medications and self-prescribing, and these drugs can lead to abuse and addiction through relieving afflictions only at the beginning of the usage. ${ }^{30,34-36}$

\section{Conclusion}

In general, research findings show that emotional distress tolerance in methamphetamine and drug abuser is lower than non-drug abuser. The limitations of this study include collecting research data with a questionnaire that may have bias and distortion in the response of individuals; only two types of drugs (methamphetamine and opioid) were studied, among other limitations of the present research we can refer to the low number of subjects and the lack of control of intrusive variables, therefore, caution should be taken in generalizing the results to other drug abuser.

It is recommended that therapists working in the field of treating substance abuse pay special attention to the level of distress tolerance among people abusing drugs besides providing medical treatments, detoxification, and other treatments of drug dependency. It is also recommended that researchers utilize an experimental study to teach people abusing opium and methamphetamine about the importance of managing stress and distress.

\section{Financial support and sponsorship}

This Study was supported by the Kermanshah University of Medical Sciences, Kermanshah, Iran (Grant no. 97214).

\section{Funding}

This Study was supported by the Kermanshah University of Medical Sciences, Kermanshah, Iran.

\section{Declaration of competing interest}

The authors declared no conflicts of interest.

\section{Acknowledgements}

The authors would like to thank the Substance abuse prevention research center and clinical Research Development Unit (CRDU) of Emam Khomeini Hospital, University of Medical sciences, Kermanshah, Iran for their cooperation and scientific assistance throughout the period of study.

\section{References}

1. Kaiser AJ, Milich R, Lynam DR, Charnigo RJ. Negative urgency, distress tolerance, and substance abuse among college students. Addict Behav. 2012;37(10):1075-1083.

2. Farnia V, Alikhani M, Jalali A, et al. The Role of attachment styles and perceived social support in prediction of methamphetamine abuse. Journal of substance use. 2018;23:378-383.

3. Farnia V, Bagher Mousavi S, Tatari F, et al. Prevalence of childhood AttentionDeficit/Hyperactivity disorder (ADHD) in methamphetamine ependence: A descriptive study. Iranian Journal of Psychiatry and Behavioral Sciences. 2018;12:e61329.

4. Farnia V, Farshchian F, Farshchian N, et al. A voxel-based morphometric brain study of patients with methamphetamine dependency: A case controlled study. NeuroQuantology. 2018;16:57-61.

5. Leyro TM, Zvolensky MJ, Bernstein A. Distress tolerance and psychopathological symptoms and disorders: a review of the empirical literature among adults. Psychol Bull. 2010;136(4):576-600.

6. Daughters SB, Sargeant MN, Bornovalova MA, Gratz KL, Lejuez CW. The relationship between distress tolerance and antisocial personality disorder among male inner-city treatment seeking substance users. J Personal Disord. 2008;22(5):509-524.

7. Keough ME, Riccardi CJ, Timpano KR, Mitchell MA, Schmidt NB. Anxiety symptomatology: the association with distress tolerance and anxiety sensitivity. Behav Ther. 2010;41(4):567-574.

8. Buckner JD, Keough ME, Schmidt NB. Problematic alcohol and cannabis use among young adults: the roles of depression and discomfort and distress tolerance. Addict Behav. 2007;32(9):1957-1963.

9. Daughters SB, Lejuez CW, Bornovalova MA, Kahler CW, Strong DR, Brown RA. Distress tolerance as a predictor of early treatment dropout in a residential substance abuse treatment facility. J Abnorm Psychol. 2005;114(4):729-734.

10. Howell AN, Leyro TM, Hogan J, Buckner JD, Zvolensky MJ. Anxiety sensitivity, distress tolerance, and discomfort intolerance in relation to coping and conformity motives for alcohol use and alcohol use problems among young adult drinkers. Addict Behav. 2010;35(12):1144-1147.

11. Daughters SB, Ross TJ, Bell RP, Yi JY, Ryan J, Stein EA. Distress tolerance among substance users is associated with functional connectivity between prefrontal regions during a distress tolerance task. Addict Biol. 2017;22(5):1378-1390.

12. Marshall-Berenz EC, Vujanovic AA, Macpherson L. Impulsivity and alcohol use coping motives in a trauma-exposed sample: the mediating role of distress tolerance. Personal Individ Differ. 2011;50(5):588-592.

13. Simons R M, Sistad R, Simons J S, Hansen J. The role of distress tolerance in the relationship between cognitive schemas and alcohol problems among college students. Addictive behaviors. 2017;78:1-8.

14. Seo JW, Kwon SM. Testing an affective judgment model of distress tolerance in college heavy drinkers. Addict Behav. 2016;58:100-103.

15. Gleber R, Vilke GM, Castillo EM, Brennan J, Oyama L, Coyne CJ. Trends in emergency physician opioid prescribing practices during the United States opioid crisis. Am J Emerg Med. 2019. https://doi.org/10.1016/j.ajem.2019.06.011 In press.

16. Levran O, Yuferov V, Kreek MJ. The genetics of the opioid system and specific drug addictions. Hum Genet. 2012;131(6):823-842.

17. Thanos PK, Kim R, Delis F, et al. Chronic methamphetamine effects on brain structure and function in rats. PLoS One. 2016;11(6):e0155457.

18. Simons J S, Gaher R M. The distress tolerance scale: development and validation of a selfreport measure. Motivation and Emotion; 2005:83-102.

19. Azizi AR. Reliability and validity of the Persian version of distress tolerance scale. Iran J Psychiatry. 2010;5(4):154-158.

20. Zvolensky MJ, Marshall EC, Johnson K, Hogan J, Bernstein A, Bonn-Miller MO. Relations between anxiety sensitivity, distress tolerance, and fear reactivity to bodily sensations to coping and conformity marijuana use motives among young adult marijuana users. Exp Clin Psychopharmacol. 2009;17(1):31-42.

21. Verdejo-Garcia A, Bechara A, Recknor EC, Perez-Garcia M. Negative emotion-driven impulsivity predicts substance dependence problems. Drug Alcohol Depend. 2007;91(2-3):213-219.

22. McKay JR. Negative mood, craving, and alcohol relapse: can treatment interrupt the process? Curr Psychiatr Rep. 2011;13(6):431-433.

23. Chen XJ, Wang CG, Liu W, Gorowska M, Wang DM, Li YH. Identification of the features of emotional dysfunction in female individuals with methamphetamine use disorder measured by musical stimuli modulated startle reflex. Front Hum Neurosci. 2018;12:230.

24. Contreras M, Ceric F, Torrealba F. The negative side of emotions: addiction to drugs of abuse. Rev Neurol. 2008;47(9):471-476.

25. Cooper ML, Frone MR, Russell M, Mudar P. Drinking to regulate positive and negative emotions: a motivational model of alcohol use. J Personal Soc Psychol. 1995;69(5):990-1005.

26. Aguilar de Arcos F, Verdejo-Garcia A, Peralta-Ramirez MI, Sanchez-Barrera M, PerezGarcia M. Experience of emotions in substance abusers exposed to images containing neutral, positive, and negative affective stimuli. Drug Alcohol Depend. 
2005;78(2):159-167.

27. Wills TA, Pokhrel P, Morehouse E, Fenster B. Behavioral and emotional regulation and adolescent substance use problems: a test of moderation effects in a dual-process model. Psychol Addict Behav. 2011;25(2):279-292.

28. Murphy A, Taylor E, Elliott R. The detrimental effects of emotional process dysre gulation on decision-making in substance dependence. Front Integr Neurosci. 2012;6:101.

29. O'Daly OG, Trick L, Scaife J, et al. Withdrawal-associated increases and decreases in functional neural connectivity associated with altered emotional regulation in alcoholism. Neuropsychopharmacol Offic Publ Am Coll Neuropsychopharmacol. 2012;37(10):2267-2276.

30. Measelle JR, Stice E, Springer DW. A prospective test of the negative affect model of substance abuse: moderating effects of social support. Psychol Addict Behav. 2006;20(3):225-233.

31. Vujanovic AA, Rathnayaka N, Amador CD, Schmitz JM. Distress tolerance: associations with posttraumatic stress disorder symptoms among trauma-exposed, cocainedependent adults. Behav Modif. 2016;40(1-2):120-143.
32. Shorey RC, Gawrysiak MJ, Elmquist J, Brem M, Anderson S, Stuart GL. Experiential avoidance, distress tolerance, and substance use cravings among adults in residential treatment for substance use disorders. J Addict Dis. 2017;36(3):151-157.

33. Khan AJ, Pedrelli P, Shapero BG, et al. The association between distress tolerance and alcohol related problems: the pathway of drinking to cope. Subst Use Misuse. 2018;53(13):2199-2209.

34. Wilens TE, Martelon M, Anderson JP, Shelley-Abrahamson R, Biederman J Difficulties in emotional regulation and substance use disorders: a controlled family study of bipolar adolescents. Drug Alcohol Depend. 2013;132(1-2):114-121.

35. Gonzalez A, Zvolensky MJ, Vujanovic AA, Leyro TM, Marshall EC. An evaluation of anxiety sensitivity, emotional dysregulation, and negative affectivity among daily cigarette smokers: relation to smoking motives and barriers to quitting. $J$ Psychiatr Res. 2008;43(2):138-147.

36. Aguilar de Arcos F, Verdejo-Garcia A, Ceverino A, et al. Dysregulation of emotional response in current and abstinent heroin users: negative heightening and positive blunting. Psychopharmacology. 2008;198(2):159-166. 